\title{
A Review of Ocular Complications Associated with Medications Used for Anxiety, Depression, and Stress
}

\author{
Paul A Constable (D), Dalia Al-Dasooqi (D), Rhiannon Bruce (D), Mallika Prem-Senthil (D) \\ Caring Futures Institute, College of Nursing and Health Sciences, Flinders University, Adelaide, Australia \\ Correspondence: Paul A Constable, Flinders University, GPO Box 2100, Adelaide, 500I, South Australia, Australia, Tel + 6I 8722 I 8398, \\ Email paul.constable@flinders.edu.au
}

\begin{abstract}
This review of commonly prescribed psychotropic drugs aims to update the clinician on possible ophthalmic side effects that may include dry eye, diplopia, mydriasis, and cataracts. This review summarizes our current knowledge of known ocular side effects of psychotropic drugs based on reviews, case reports, case-control studies, a case series, and cross-sectional observational studies reported in the recent literature. The review covers disorders related to depression, anxiety, and stress which are commonly encountered within society and can have debilitating impacts on an individual's quality of life that may require chronic therapeutic management. The main medications used in the treatment and management of these conditions typically target receptors, metabolic enzymes, or transport pumps that alter the pre- and/or post-synaptic levels of neurotransmitters such as serotonin, norepinephrine, dopamine, gammaaminobutyric acid, and opioids to improve mood and/or relieve pain and anxiety. Novel non-therapeutic options are undergoing clinical trials, and some patients may seek alternative therapies or have associated substance abuse issues to alleviate their symptoms. This review summarizes some of the clinical signs of depression and the main therapeutic options and their reported ocular side effects which may be pertinent today given the rise in use of psychotropic medications used to manage depression, anxiety, and stress.
\end{abstract}

Keywords: drugs, ocular, psychotropic, side effects

The coronavirus pandemic has had a significant impact on mental health across the population and those involved with primary care. ${ }^{1}$ The global pandemic has caused an increase in psychological distress worldwide over the last two years, with physical isolation and fear of infection contributing to the exacerbation of mental health disorders. ${ }^{2}$ The pandemic is estimated to have increased the prevalence of mental health issues by $6 \%$ globally, with increased suicide risk, alcohol consumption, and diagnosed major depressive disorder. ${ }^{1}$

The main aim of this review is to provide an update to common side effects of psychotropic medications whose use has increased in line with the greater prevalence of mental health disorders. ${ }^{3}$ The last comprehensive review into the ocular side effects of psychotropic medications was published in $2010 .^{4}$ Since then, monoamine oxidase inhibitors and tricyclic antidepressants are used less commonly, with the selective or non-selective serotonin (5-hydroxytryptamine) and norepinephrine reuptake pumps being more frequently prescribed for disorders associated with depression, anxiety, and stress. ${ }^{5}$ Often these conditions form a comorbid association and may require a combination of therapeutics for extended periods of time to manage the symptoms, resulting in a higher risk of ocular and systemic side effects. ${ }^{6}$ Psychotropic therapeutics may also be used in conditions such as schizophrenia, bipolar disorder, autism spectrum disorder, and attention deficit hyperactivity disorder, and these individuals may also experience ocular side effects from medications aimed at managing their associated mental health issues. ${ }^{7-10}$

The pathophysiology of depression and anxiety is not fully understood, with a multifactorial aetiology related to stress, genetics (based on familial and twin studies), and environmental factors such as experiencing a traumatic event all being implicated. ${ }^{11-14}$ At a structural level a reduction in the pre-frontal cortical volume was observed using 
a combination of imaging techniques and histopathological post-mortem cortical samples that revealed a decreased neuronal size and glial cell densities in brains of subjects with major depressive disorder. ${ }^{15,16}$ Further studies performed with gene arrays also showed a reduced expression profile for genes involved with synaptic plasticity and excitability contributing to depression. ${ }^{16,17}$ Furthermore, decreased levels of the brain-derived neurotrophic growth factors may increase stress vulnerability of neurons within the cortex which is found in depression and offer potential new therapeutic targets. ${ }^{18,19}$ Brain-derived neural growth factor is released rapidly by ketamine, which has recently been used to treat severe depression. ${ }^{20}$ Epigenetic markers, transcription factors, and inflammatory pathways have all been implicated in depression. ${ }^{13,19}$ The reader is directed to Ménard et $\mathrm{al}^{21}$ and Malhi and Mann ${ }^{3}$ for comprehensive reviews of these mechanisms based on human and animal models.

Antidepressants target receptors and pumps for neurotransmitters at neural synapses that modulate the concentration of the neurotransmitter, which changes signal transduction and downstream secondary signaling pathways that may lead to long-term transcriptional changes of enzymes and receptors. ${ }^{21,22}$ All available antidepressants act on presynaptic and postsynaptic receptors and neurotransmitter transporters. ${ }^{3}$ Consequently, the concentration of neurotransmitters within the synapse or within the presynaptic neuron is altered. ${ }^{16}$ Antidepressants may further stimulate neurogenesis via neurotrophic growth factors and change neural networks within the hippocampus that plays a major role in memory and learning and is affected by stress. ${ }^{23,24}$

Tricyclic antidepressants monoamine oxidase inhibitors, benzodiazepines, and selective serotonin reuptake inhibitors (SSRIs) are the main drug classes used to treat and manage depression, anxiety, and stress-related disorders. The tricyclic antidepressants include amitriptyline, clomipramine, dosulepin, doxepin, imipramine, and nortriptyline. However, the tricyclic antidepressants also act on histamine, acetylcholine, and norepinephrine receptors, which may result in drowsiness, constipation, and ocular side effects such mydriasis through their cholinergic and adrenergic actions. ${ }^{25}$

The SSRIs include citalopram, escitalopram, fluoxetine, fluvoxamine, paroxetine, and sertraline and are used primarily to manage depression and anxiety and have fewer side effects than the tricyclic antidepressants and monoamine oxidase inhibitors. ${ }^{25}$ The mechanism of action is to prevent reuptake of serotonin by inhibiting the uptake pumps in neurons. ${ }^{26}$ The serotonin and norepinephrine reuptake inhibitors (SNRIs) act by also inhibiting the uptake pumps for serotonin and norepinephrine and have similar clinical efficacy in anxiety disorders. ${ }^{27}$ The SSRIs and SNRIs have greater selectivity than the tricyclic and monoamine oxidase antidepressants and therefore are associated with fewer systemic side effects such as cardiovascular complications; therefore they have a better safety profile. ${ }^{28}$

The benzodiazepines include temazepam, nitrazepam, diazepam, oxazepam, and alprazolam and may be used in the treatment of anxiety and stress. The mechanism of action is through binding to gamma-aminobutyric acid receptors subtype-A which inhibits neural activity in the cortex to induce a sedative effect and thereby alleviate the symptoms of anxiety and stress. ${ }^{29}$

Current definitions of mental health are classified by the Diagnostic and Statistical Manual of Mental Disorders-5 in which a mental health disorder is defined as

a syndrome characterized by clinically significant disturbance in an individual's cognition, emotional regulation, or behavior that reflects a dysfunction in the psychological, biological, or developmental process underlying mental functioning. ${ }^{30}$

The main mental health conditions considered in this review are related to depression, anxiety, and stress-related disorders which often overlap within an individual. ${ }^{31}$ Of those with a diagnosis of a mental health condition up to a half will have a secondary comorbid mental health condition, and suffer from substance abuse, diabetes, lung disease, or hypertension, and thus it is important to consider the impact of mental health conditions on the patients' overall wellbeing and the negative impact on their overall quality of life owing to the associated comorbidities. ${ }^{32}$

Depression may manifest because of long-term illness, substance abuse, or be a combination of socio-economic and genetic risk factors. ${ }^{3,13,14}$ Depression is diagnosed based on a range of symptoms that may manifest as core symptoms of depressed mood and anhedonia (a reduced motivation to experience pleasure) that may be combined with emotional, neurovegetative, and neurocognitive symptoms including suicidal ideation, insomnia, and agitation. ${ }^{3}$ Anxiety may be evoked by uncertainty or perceived threat that evokes a physiological response or avoidance strategy to cope with the anxiety. ${ }^{33}$ Anxiety disorders are prevalent in all age groups and are often associated with substance abuse and 
comorbidities such as depression. ${ }^{32}$ Symptoms of anxiety disorders include restlessness and feeling on edge, fatigue, irritability, muscle tension, insomnia, and difficulty with concentration. ${ }^{30,33}$ Stress disorders such as post-traumatic stress disorder are the direct result of some traumatic or stressful event that may result in effects on the individual's physiology and/or state of mind. ${ }^{34,35}$

The last main review of psychotropic medications and their ocular side effects was conducted in 2010 and included the most prescribed psychotropic medications classified as antidepressants, antipsychotics, and mood stabilizers in use since 1960. Ocular structures were isolated, and the effects of psychotropic drugs were categorized accordingly. ${ }^{4}$ One systematic review was on systemic medications and their ocular side effects although the complications associated with psychotropic medications were limited owing to the broad scope of the review. ${ }^{36}$ The main aim of this review is to summarize the key ophthalmic findings related to depression, anxiety, and stress and note some potential future nontherapeutic means of managing depression. For the search strategy used and summary of the main study findings in this review see the Supplementary Material.

Table 1 lists common medications and their drug class and therapeutic indications currently in use.

\section{Depression}

SSRIs and SNRIs are used as first-line treatment for depression due to their increased drug safety profile and efficacy in children and adults. ${ }^{3,37}$ SSRIs have been known to induce and exacerbate depression-related dry eye by interference with aqueous and mucus secretion, by competing with acetylcholine at postsynaptic muscarinic receptors and reducing the signaling of tear component secretion resulting in tear film instability. ${ }^{38}$ High levels of serotonin in the tear film can contribute to ocular surface inflammatory markers and apoptosis in human corneal epithelial cell culture. ${ }^{39,40}$ In a human study, Acan and Kurtgoz ${ }^{38}$ compared tear film parameters in individuals on SSRIs for anxiety and/or depression with a comparison cohort and found significant group differences, with $75 \%$ of patients taking SSRIs having a tear break-up time of less than ten seconds $(p<0.001)$ and greater superficial corneal epithelial punctuate staining using the Oxford schema $(p<0.001)$ but no significant group differences in the Schirmer 1 test. These findings suggested that tear production was not compromised but serotonin affected the ocular surface primarily and potentially through reduced corneal sensitivity. ${ }^{38}$

Several clinical studies have been performed to evaluate the association between dry eye disease and depression and anxiety. The largest study by van der Vaart et $\mathrm{al}^{41}$ found that the odds ratio for dry eye disease and anxiety and depression was 2.8 and 2.9, respectively. Similar odds ratios of 1.97 and 1.91 were also observed in a retrospective study of war veterans suffering from post-traumatic stress disorder or depression, respectively. ${ }^{42}$ Furthermore, in 472 psychiatric patients with depression and anxiety disorders there was a significant association with dry eye disease with use of SSRIs $(p<0.007) .{ }^{43}$ Zhang et al $^{44}$ also report in a small study of twenty subjects increased corneal staining in subjects using SSRIs for depression supporting the proposal that dry eye disease in individuals using SSRIs is due to a breakdown of the ocular surface with epithelial apoptosis. ${ }^{44}$ Wan et $\mathrm{al}^{45}$ performed a systematic review with the relationship between dry eye disease and depression and anxiety and found an overall odds ratio of 2.92 and 2.82, respectively, from twentytwo included studies. Overall, there is strong evidence that individuals with a diagnosis of anxiety/depression are approximately twice as likely to suffer from dry eye disease. ${ }^{41}$

Antidepressants have also been implicated in formation of cataract through epidemiological studies. ${ }^{46-50}$ However, Zanon-Moreno et $\mathrm{al}^{51}$ assayed levels of serotonin in the aqueous humor of thirty age- and sex-matched patients with a diagnosis of either cataract or primary open angle glaucoma and found no significant differences between the groups, suggesting no direct association with aqueous humor serotonin concentration and the risk of cataract or primary open angle glaucoma. Nonetheless, the first evidence for a link between cataracts and antidepressants came from the Beaver Dam Eye Study where the tricyclic antidepressant amitriptyline had an odds ratio of 2.03 for cortical cataracts. ${ }^{50}$ These findings have been supported by several epidemiological studies that investigated the link between SSRIs and cataract. In a large population-based case-control study the relative risk of developing cataracts was 1.15 with greater risk of developing cataracts associated with the SSRIs (fluvoxamine $>$ venlafaxine $>$ paroxetine), although the authors did not control for smoking and could not exclude this factor as a possible confounding risk factor. ${ }^{49}$ Another population-based case-control study found that the use of a SSRI for more than 
Table I Common Therapeutics Used in the Treatment and Management of Anxiety, Depression, and Stress

\begin{tabular}{|c|c|c|}
\hline Drug Class & Name & Therapeutic Indication \\
\hline \multirow{6}{*}{$\begin{array}{l}\text { Tricyclic } \\
\text { antidepressants }\end{array}$} & Amitriptyline (Endep, Entrip) & Severe depression, neuropathic pain, post-traumatic stress disorder \\
\hline & Clomipramine (Anafranil, Placil) & Severe depression, obsessive compulsive disorder, phobias, panic disorders \\
\hline & Doxepin (Deptran, Sinequan) & $\begin{array}{l}\text { Severe depression, neuropathic pain, obsessive compulsive disorder, panic disorder, } \\
\text { generalized anxiety disorder, phobias, post-traumatic stress disorder }\end{array}$ \\
\hline & Nortriptyline (Allegron, NortriTABS) & Severe depression, neuropathic pain \\
\hline & Imipramine (Tofranil, Tolerade) & Severe depression, generalized anxiety disorder, panic disorder \\
\hline & Dosulepin/dothiepin (Dothep) & Severe depression with anxiety \\
\hline \multirow[t]{3}{*}{$\begin{array}{l}\text { Monoamine } \\
\text { oxidase inhibitors }\end{array}$} & Tranylcypromine (Parnate) & $\begin{array}{l}\text { Major depressive disorders, some anxiety disorders including phobic and panic } \\
\text { disorders }\end{array}$ \\
\hline & $\begin{array}{l}\text { Moclobemide (Reversible inhibitor of } \\
\text { Monoamine oxidase) }\end{array}$ & Depressive disorders, panic disorders \\
\hline & Phenelzine (Nardil) & Depression \\
\hline \multirow[t]{6}{*}{ SSRIs } & $\begin{array}{l}\text { Citalopram (Celapram, Celica, } \\
\text { Cipramil, Talam) }\end{array}$ & \multirow{6}{*}{$\begin{array}{l}\text { Major depressive disorders, generalized anxiety disorder, bipolar depression, } \\
\text { obsessive compulsive disorder, panic disorders, post-traumatic stress disorder, } \\
\text { social phobia }\end{array}$} \\
\hline & $\begin{array}{l}\text { Fluoxetine (Fluotex, Lovan, Prozac, } \\
\text { Prozet, Zactin) }\end{array}$ & \\
\hline & $\begin{array}{l}\text { Fluvoxamine (Facerin, Luvox, Movox, } \\
\text { Voxam) }\end{array}$ & \\
\hline & $\begin{array}{l}\text { Paroxetine (Aropax, Extine, Paxtine, } \\
\text { Roxet, Roxtine) }\end{array}$ & \\
\hline & $\begin{array}{l}\text { Sertraline (Eleva, Sertra, Sertracor, } \\
\text { Setrona, Xydep, Zoloft) }\end{array}$ & \\
\hline & Escitalopram (Lexapro) & \\
\hline \multirow[t]{3}{*}{ SNRIs } & $\begin{array}{l}\text { Venlafaxine (Altven, Efexor-XR, } \\
\text { Elaxine, Enlafax-XR) }\end{array}$ & $\begin{array}{l}\text { Major depression, generalized anxiety disorder, panic disorder, social anxiety } \\
\text { disorder }\end{array}$ \\
\hline & $\begin{array}{l}\text { Desvenlafaxine (Desfax, Desven, } \\
\text { Pristiq) }\end{array}$ & Major depression \\
\hline & $\begin{array}{l}\text { Duloxetine (Andepra, Coperin, } \\
\text { Cymbalta, Depreta, Dytrex, Tixol) }\end{array}$ & Major depression, generalized anxiety disorder, neuropathic pain \\
\hline \multirow[t]{6}{*}{ Benzodiazepines } & Temazepam (Euhypnos, Normison) & Short-term insomnia \\
\hline & Nitrazepam (Alodorm, Mogadon) & Insomnia \\
\hline & Diazepam (Valium, Ducene) & Short-term management of anxiety and agitation \\
\hline & $\begin{array}{l}\text { Oxazepam (Alepam, Murelax, } \\
\text { Serepax) }\end{array}$ & Anxiety \\
\hline & Alprazolam (Xanax) & Anxiety, panic disorder \\
\hline & Lorazepam (Ativan) & Anxiety, and short-term treatment of insomnia \\
\hline
\end{tabular}

(Continued) 
Table I (Continued).

\begin{tabular}{|l|l|l|}
\hline Drug Class & Name & Therapeutic Indication \\
\hline \multirow{4}{*}{$\begin{array}{l}\text { Typical } \\
\text { antipsychotics }\end{array}$} & $\begin{array}{l}\text { Risperidone (Risperdal, Rispa, } \\
\text { Rixadone) }\end{array}$ & $\begin{array}{l}\text { Schizophrenia and related psychoses, short-term treatment of acute mania } \\
\text { associated with bipolar disorder }\end{array}$ \\
\cline { 2 - 3 } & Aripiprazole (Abilify, Abyraz) & Schizophrenia, bipolar disorder \\
\cline { 2 - 3 } & Clozapine (Clozaril) & Schizophrenia \\
\cline { 2 - 3 } & \begin{tabular}{l} 
Olanzapine (Zyprexa, Pryzex) \\
\cline { 2 - 3 }
\end{tabular} & $\begin{array}{l}\text { Schizophrenia and related psychoses, short-term treatment of acute mania } \\
\text { associated with bipolar disorder }\end{array}$ \\
\cline { 2 - 3 } & XR, Tevatiapine XR) & Bipolar disorder \\
\cline { 2 - 3 } & $\begin{array}{l}\text { Ziprasidone (Zeldox, Ziprox) } \\
\text { Gamma- } \\
\text { aminobutyric acid } \\
\text { analogues }\end{array}$ & $\begin{array}{l}\text { Schizophrenia and related psychoses, short-term treatment of acute mania } \\
\text { associated with bipolar disorder }\end{array}$ \\
\cline { 2 - 3 } & Pregabalin (Lyrica) & Epilepsy, neuropathic pain \\
\hline
\end{tabular}

a year led to an increase in risk of cataract surgery with an odds ratio of $1.36 .{ }^{48}$ Chou et al ${ }^{47}$ performed a large nested case-control study in patients with schizophrenia or mood disorder and either cataract or no cataract and using antidepressants including tricyclic antidepressants, SSRIs, and/or SNRIs. The authors found the adjusted odds ratios for the development of cataract were similar across the drug classes (1.26 for SSRIs, 1.21 for SNRIs, and 1.18 for tricyclic antidepressants) with greatest risk in those individuals using the SSRI fluvoxamine (1.47) ${ }^{47}$ In contrast, an observational study found a weak adjusted odds ratio of 1.24 associated with long-term SSRI use (greater than twenty prescriptions) with cataract in the younger subset of patients aged between forty and sixty-five years of age, and the authors concluded that there was a need to explore the association with cataract and antidepressants further, given there was no increased risk when all age groups were included. ${ }^{46}$ Finally, one case of rapid bilateral cataract formation has been reported in a teenage patient taking the SSRI fluvoxamine daily over a period of seven months. ${ }^{52}$ Thus the direct association with cataract formation and use of antidepressants is confounded by associated risk factors such as smoking, family history, systemic steroid use, and ultra-violet light exposure which may mask the true influence of antidepressants and cataract formation; however, future work may clarify the direct risk of cataract formation with antidepressant use. ${ }^{46}$

The sphincter pupillae muscle is relaxed by serotonin, noradrenergic, and anticholinergic effects, which are all induced by tricyclic antidepressants, SSRIs, and SNRIs. ${ }^{53}$ However, SSRI-induced mydriasis does not appear to cause significant visual discomfort when not associated with acute angle closure glaucoma. ${ }^{4}$ Patients using SNRIs have been found to have a larger pupil diameter, a shallower anterior chamber depth, and a lower intra-ocular pressure over long-term usage. ${ }^{54}$ Individuals with narrow anterior chamber angles are more predisposed to acute angle closure attacks of the anterior chamber angle when using tricyclic antidepressants, and to a lesser extent SSRIs. ${ }^{53}$ Chen et al ${ }^{55}$ found that patients beginning SSRI therapy have a substantially higher risk (5.8-fold) of acute angle closure compared to non-users, and this was higher if the daily dose was greater than $20 \mathrm{mg}$ per day.

Zheng et $\mathrm{al}^{56}$ reported a strong reduction in risk of primary open angle glaucoma in a retrospective study of patients using SSRIs and found a reduced odds ratio of 0.70 of requiring glaucoma management. One antidepressant, bupropion, a dopamine reuptake inhibitor, appears to reduce the risk of primary angle closure glaucoma. ${ }^{57} \mathrm{~A}$ large retrospective study indicated that the risk of developing open angle glaucoma was reduced by $21 \%$ in patients taking bupropion for more than one year with no increased risk for open angle glaucoma in patients using other SSRIs or tricyclic antidepressants. ${ }^{58}$ More recently Masís et $\mathrm{al}^{59}$ performed a cross-sectional study in participants and found a reduced 
risk of a glaucoma diagnosis with an adjusted odds ratio of 0.1 in those using bupropion for more than a year, which may be due to its role in reducing the pro-inflammatory mediator, tumour necrosis factor. ${ }^{59}$ Thus long-term use of SSRIs may provide some protection against primary open angle glaucoma.

Rare complications of SSRIs include oculogyric crises ${ }^{60}$ with one case report of a twenty-year-old patient on longterm quetiapine experiencing approximately ten attacks per month, both abrupt and painful in nature, which reduced upon decreasing the dosage of the drug. ${ }^{61}$ There is one case report of an acute angle closure glaucoma within the first hour after taking the SSRI mirtazapine. ${ }^{62}$ In addition, rare oculomotor complications have been reported, with one case report of diplopia in a patient taking the SSRI citalopram who was immunocompromised ${ }^{63}$ and in one veteran who was prescribed sertraline for post-traumatic stress disorder who developed diplopia which resolved following a change of medication to a SNRI. ${ }^{64}$

Rare side effects of SNRIs have been reported: one of a forty-four-year-old female who experienced unilateral vision loss due to retrobulbar optic neuritis whilst on duloxetine; and the other of an eighty-one-year-old female who developed bilateral acute angle closure, two days after also commencing duloxetine. ${ }^{65,66}$ Venlafaxine, a SNRI, resulted in an intraocular pressure of $50 \mathrm{mmHg}$ in the right eye of one male patient and $30 \mathrm{mmHg}$ in the left eye after being managed for open angle glaucoma with latanoprost. ${ }^{67} \mathrm{~A}$ binocular horizontal pendular nystagmus developed in a fifty-four-year old female taking venlafaxine for mild depression. ${ }^{68}$

Thus, the SSRIs and SNRIs have a strong association with dry eye disease owing to disruption of the ocular surface with a possible link to cataract formation, but further studies are required. Angle closure glaucoma attacks have been reported and are more likely in the first month of commencing a SSRI and at a dose $>20 \mathrm{mg} /$ day. ${ }^{55}$

\section{Anxiety and Stress}

Anxiety disorders are one of the most common psychiatric disorders, with subtypes ranging from social, panic, and generalized anxiety disorders. As with depressive disorders, the first-line treatment for anxiety disorders are the SSRIs with SNRIs. ${ }^{5,69}$ However, the tricyclic antidepressants which function as norepinephrine and serotonin reuptake inhibitors were one of the first classes of medications used for anxiety disorders. ${ }^{25}$ Mydriasis is a common ocular side effect of the tricyclic antidepressants owing to their anticholinergic properties resulting in pupil dilation and possible blurry vision. ${ }^{4,70}$ Tricyclic antidepressants have involvement in acute angle closure and a precipitation to acute angle closure glaucoma due to pupillary block secondary to pupillary dilatation. ${ }^{57}$ These anticholinergic effects from tricyclic antidepressant use may also result in blockage of the trabecular meshwork and blurred vision from loss of accommodation. ${ }^{70}$ Given the risk of using medications with such potent anticholinergic properties, selecting newer classes of antidepressants (SSRI and SNRI) can provide crucial alternatives, or even in the case of tricyclic antidepressants the use of those with less anticholinergic effects such as desipramine and nortriptyline can present a lesser risk. ${ }^{71}$ For review see Ciobanu et $\mathrm{al}^{71}$ and $\mathrm{Wu}$ et al. ${ }^{57}$

Benzodiazepines are also a widely used treatment for anxiety in the past and are still amongst the most widely prescribed class of psychotropic drugs in the world. ${ }^{69}$ Benzodiazepines, which act as gamma-aminobutyric acid agonists, are restricted to short-term treatment mostly of acute anxiety or on an as-needed basis for social anxiety disorders, panic disorders, and generalized anxiety disorders in conjunction with SSRIs and SNRIs. This is due to some associated adverse effects especially when benzodiazepines are used for extended periods of time in high doses. Another frequently used benzodiazepine, alprazolam, has been linked to a higher risk of bilateral acute angle closure glaucoma occurrence due to the influence that benzodiazepine has on the sphincter pupillae and the subsequent narrowing of the iridocorneal angle. ${ }^{71}$ A case report has described diplopia in a patient with depression and obsessive-compulsive disorder using lorazepam. ${ }^{72}$ Furthermore, one recent case report was of a twenty-one-year-old woman with underlying anxiety disorder who presented with a one-week history of light-headedness and blurred vision due to dilated pupils that were not responsive to light or accommodation that was reversed on cessation of alprazolam. ${ }^{73}$

Monoamine oxidase inhibitors are also an older antidepressant that is now typically used as a third-line option due to significant adverse side effects. An overdose of this drug was found to result in a short-cycle periodic alternating gaze, also known as ping-pong gaze. It was defined as a slow conjugate deviation of the eyes from one extreme to the other in a fixed frequency and without pause. ${ }^{74}$ 
Table 2 Common Ocular Side Effects Associated with Therapeutics Used for the Treatment and Management of Depression, Anxiety, and Stress

\begin{tabular}{|c|c|c|}
\hline Drug Class & Name & Ocular Side Effect \\
\hline \multirow[t]{7}{*}{$\begin{array}{l}\text { Tricyclic } \\
\text { antidepressants }\end{array}$} & Chlorpromazine & $\begin{array}{l}\text { Decreased lacrimation and dry eye, mydriasis, cataracts, blurred vision, corneal } \\
\text { oedema, corneal epithelial keratopathy, abnormal pigmentation of the eyelids/ } \\
\text { conjunctiva/cornea/peripheral retina }{ }^{2}\end{array}$ \\
\hline & Amitriptyline (Endep, Entrip) & \multirow{6}{*}{$\begin{array}{l}\text { Decreased lacrimation and dry eye, mydriasis, blurred vision, cataracts, acute angle } \\
\text { closure due to pupil block (amitriptyline, imipramine) }\end{array}$} \\
\hline & Clomipramine (Anafranil, Placil) & \\
\hline & Doxepin (Deptran, Sinequan) & \\
\hline & Nortriptyline (Allegron, NortriTABS) & \\
\hline & Imipramine (Tofranil, Tolerade) & \\
\hline & Dosulepin/dothiepin (Dothep) & \\
\hline \multirow{3}{*}{$\begin{array}{l}\text { Monoamine } \\
\text { oxidase inhibitors }\end{array}$} & Tranylcypromine (Parnate) & \multirow{3}{*}{$\begin{array}{l}\text { Blurred vision } \\
\text { Rare: occipital headache, ping-pong gaze (phenelzine) }\end{array}$} \\
\hline & $\begin{array}{l}\text { Moclobemide (Reversible inhibitor of } \\
\text { Monoamine oxidase) }\end{array}$ & \\
\hline & Phenelzine (Nardil) & \\
\hline \multirow[t]{6}{*}{ SSRIs } & $\begin{array}{l}\text { Citalopram (Celapram, Celica, } \\
\text { Cipramil, Talam) }\end{array}$ & \multirow{6}{*}{$\begin{array}{l}\text { Dry eye, mydriasis, intraocular pressure elevation, acute angle closure crisis } \\
\text { Rare: ocular dystonia, oculogyric crisis, diplopia, optic neuropathy, maculopathy } \\
\text { (sertraline), eyelash loss (escitalopram) }\end{array}$} \\
\hline & Escitalopram (Lexapro) & \\
\hline & $\begin{array}{l}\text { Fluoxetine (Fluotex, Lovan, Prozac, } \\
\text { Prozet, Zactin) }\end{array}$ & \\
\hline & $\begin{array}{l}\text { Fluvoxamine (Facerin, Luvox, Movox, } \\
\text { Voxam) }\end{array}$ & \\
\hline & $\begin{array}{l}\text { Sertraline (Eleva, Sertra, Sertracor, } \\
\text { Setrona, Xydep, Zoloft) }\end{array}$ & \\
\hline & $\begin{array}{l}\text { Paroxetine (Aropax, Extine, Paxtine, } \\
\text { Roxet, Roxtine) }\end{array}$ & \\
\hline \multirow[t]{3}{*}{ SNRIs } & $\begin{array}{l}\text { Venlafaxine (Altven, Efexor-XR, } \\
\text { Elaxine, Enlafax-XR) }\end{array}$ & \multirow{3}{*}{$\begin{array}{l}\text { Dry eye, blurred vision, mydriasis, shallow anterior chamber depth, cataracts, } \\
\text { intraocular pressure depression, acute angle-closure crisis (venlafaxine, duloxetine) } \\
\text { Rare: retrobulbar optic neuritis (duloxetine), pendular nystagmus (venlafaxine) }\end{array}$} \\
\hline & $\begin{array}{l}\text { Desvenlafaxine (Desfax, Desven, } \\
\text { Pristiq) }\end{array}$ & \\
\hline & $\begin{array}{l}\text { Duloxetine (Andepra, Coperin, } \\
\text { Cymbalta, Depreta, Dytrex, Tixol) }\end{array}$ & \\
\hline
\end{tabular}


Table 2 (Continued).

\begin{tabular}{|c|c|c|}
\hline Drug Class & Name & Ocular Side Effect \\
\hline \multirow[t]{6}{*}{ Benzodiazepines } & Lorazepam (Ativan) & \multirow{6}{*}{$\begin{array}{l}\text { Blurred vision, increased risk of bilateral acute angle closure } \\
\text { Rare: impaired tracking (alprazolam), diplopia (lorazepam) }\end{array}$} \\
\hline & Temazepam (Euhypnos, Normison) & \\
\hline & Nitrazepam (Alodorm, Mogadon) & \\
\hline & Diazepam (Valium, Ducene) & \\
\hline & $\begin{array}{l}\text { Oxazepam (Alepam, Murelax, } \\
\text { Serepax) }\end{array}$ & \\
\hline & Alprazolam (Xanax) & \\
\hline \multirow[t]{6}{*}{$\begin{array}{l}\text { Atypical } \\
\text { antipsychotics }\end{array}$} & $\begin{array}{l}\text { Risperidone (Risperdal, Rispa, } \\
\text { Rixadone) }\end{array}$ & \multirow[t]{6}{*}{$\begin{array}{l}\text { Blurred vision, mydriasis, decreased lacrimation (clozapine), cataracts (quetiapine) } \\
\text { Rare: floppy iris syndrome, oculogyric crisis }\end{array}$} \\
\hline & Aripiprazole (Abilify, Abyraz) & \\
\hline & Clozapine (Clozaril) & \\
\hline & Olanzapine (Zyprexa, Pryzex) & \\
\hline & $\begin{array}{l}\text { Quetiapine (Seroquel, Syquet, Quetia } \\
\text { XR, Tevatiapine XR) }\end{array}$ & \\
\hline & Ziprasidone (Zeldox, Ziprox) & \\
\hline \multirow{2}{*}{$\begin{array}{l}\text { Gamma- } \\
\text { aminobutyric acid } \\
\text { analogues }\end{array}$} & Pregabalin (Lyrica) & $\begin{array}{l}\text { Blurry vision, diplopia } \\
\text { Rare: bilateral macular detachment, visual hallucinations }\end{array}$ \\
\hline & Gabapentin (Aspen) & Nystagmus, increased risk of angle closure glaucoma \\
\hline
\end{tabular}

Pregabalin is used in generalized anxiety disorder, as it is thought to act on alpha-2 delta subunits of voltagedependent calcium channels as a neurotransmitter release inhibitor ${ }^{75}$ and is potentially efficacious in social anxiety disorders at certain dosages. ${ }^{76}$ Blurry vision and diplopia are some of the more common effects secondary to pregabalin use reported in a systematic review by Zaccara et al. ${ }^{77}$ Rarer side effects following pregabalin overdose include a case of bilateral visual disturbance secondary to bilateral macular detachment as reported in a twenty-four-year-old female. ${ }^{78}$ Pregabalin-induced acute visual hallucinations have also been reported in a case report of a thirty-six-year-old female. ${ }^{79}$ Another anticonvulsant, gabapentin, has been used as an off-label anxiolytic in patients with severe panic symptoms in panic disorders and in social anxiety disorder that reduces neurotransmitter release by inhibiting voltage-gated calcium channels in neurons. ${ }^{69}$ Gabapentin was associated with an increased relative risk of 1.42 in developing angle closure glaucoma if used for more than one year in a large nested case-control study, but not the similarly acting pregabalin. ${ }^{80}$

The first-line pharmacological treatment for post-traumatic stress disorder includes antidepressant medications and include the SSRIs and SNRIs such as sertraline, paroxetine, fluoxetine, and venlafaxine that result in small, but clinically significant, benefits in treatment of post-traumatic stress disorder. ${ }^{35}$

Table 2 summarizes the main antidepressants and their associated ocular side effects.

\section{Discussion}

The prevalence rates of depression, anxiety, and stress-related disorders have been exacerbated by the recent coronavirus pandemic ${ }^{1,81}$ despite remaining relatively constant at approximately $4 \%$ between 1990 and $2010 .{ }^{82}$ Over the last decades there has been a shift towards the use of SSRIs and SNRIs in the management of depression and anxiety given their more specific receptor targets and reduced side effects compared to earlier drug classes including the tricyclic antidepressants and monoamine 
oxidase inhibitors. ${ }^{25}$ A large systematic review and meta-analysis of randomized controlled trials found greater levels of systemic side effects such as dry mouth and drowsiness in the studies using tricyclic antidepressants than in those using SSRIs. ${ }^{37}$

The main ocular side effects of SSRIs are dry eye and a possible risk of the development of cataract. The presumed pathophysiology is the upregulation of serotonin found in tear film and the aqueous that induces inflammatory and apoptotic pathways in the corneal epithelium and lens fibres. ${ }^{22,44}$ Rare complications may include raised intra-ocular pressure and possible angle closure glaucoma, and patients with narrow angles or currently being managed for glaucoma may require more frequent monitoring. ${ }^{54,55,66,67,71,80}$ Extremely rarely oculomotor complications such as oculogyric crises have been reported with paralysis typically in up-gaze. ${ }^{60,61}$

A higher risk for cataract formation has been shown in epidemiological and case-control studies with the use of antidepressants. ${ }^{46-50}$ However, despite controlling for many factors such as age and sex, other confounding factors may also contribute to the higher prevalence of cataracts observed in some populations such as using multiple antidepressants and lifestyle factors. Of the SSRIs fluvoxamine appears to have the greatest association with cataract formation. ${ }^{49,52}$

Although not specified as part of the search, the use of methylphenidate in attention hyperactivity disorder is commonly prescribed alongside melatonin to assist with sleeping and is presumed to increase dopamine in the striatum. ${ }^{83}$ There are no strong ocular adverse effects reported for this medication to date beyond increase in tearing. ${ }^{84}$ Schizophrenia may be treated with a combination of medication that targets dopamine, glutamate, and the serotonin receptors to modulate mood and behaviours, ${ }^{85}$ with the main side effects of medications related to weight-gain and sedation. ${ }^{86}$ Bipolar disorder may be managed with lithium which is known to cause ocular side effects such as nystagmus but provides long-term mood stabilization. ${ }^{9}$ Park et $\mathrm{al}^{10}$ reviewed reported ocular side effects of lithium and found associations with exophthalmos, binocular motility, myasthenia gravis, papilledema, photophobia, and tear film abnormalities.

Depression and anxiety are often associated with obesity, smoking, excess alcohol or illicit drug use that can pose additional risks to ocular health. Obesity and depression often co-occur with a complex and synergistic underlying pathophysiology related to metabolism, hormones, the microbiome, immune response, genetics, and brain circuitry that integrates mood with homeostatic responses. ${ }^{87} \mathrm{~A}$ recent systematic review by Fluharty et al ${ }^{88}$ found no strong causal relationship between smoking early in life and later depression, or that depression led to an increase in smoking. However, smoking cessation results in a decrease in symptoms of depression, and eye-care workers should aim to promote cessation strategies within their practice to not only reduce the risks to ocular health but also in reducing depression. ${ }^{89}$ Certainly alcohol abuse is greater in patients with depression and may pose a risk factor to ocular disease. ${ }^{90}$ Illicit drug use and depression involving cannabis, heroin, fentanyl, ketamine, cocaine, methamphetamine, and "ecstasy" (methylenedioxymethamphetamine) may also be a part of the patient profile that can cause ocular side effects from hemianopia and corneal anesthesia to cranial nerve palsies. ${ }^{32,91,92}$

Patients may also use herbal remedies for the treatment or management of psychiatric disorders, although there is a lack of double-blind randomized controlled studies to demonstrate a clear efficacy, and such remedies may have unknown drug-drug interactions and interactions with metabolic enzymes. ${ }^{93,94}$ Future clinical therapeutics are being developed to improve the selectivity of the therapeutics used in the treatment and management of anxiety and depression. ${ }^{95}$ New therapies for the treatment of depression are aimed at the glutamate system, with antagonists such as ketamine that target N-methyl-D-aspartate receptors, able to act quickly, and nasal esketamine sprays have been approved for individuals with depression that is not controlled by current therapies, ${ }^{20,96}$ although the long-term possible side effects of their use are yet to be fully evaluated. ${ }^{97}$

Tetrahydrocannabinol and cannabidiol derived from Cannabis sativa are potential new therapies for anxiety and depression, with cannabidiol not having the same addictive profile as tetrahydrocannabinol. ${ }^{98}$ Future non-therapeutic means to treat and manage depression may involve prefrontal transcranial direct current and magnetic stimulation, ${ }^{99}$ and transcranial laser stimulation with infrared light that has a photobiological modulation effect on neurons has also been employed to improve cognitive function and emotional wellbeing. ${ }^{100}$

\section{Conclusion}

The increased use of antidepressants within the community may result in more patients presenting with ocular complications of their therapeutics. Whilst severe side effects are uncommon, dry eye disease may be 
a complication that can be managed by eye-care professionals. Alternative therapies are being developed that may not result in adverse side effects, such as direct current transcranial stimulation or near infrared photo-biological modulation. In patients who are depressed or anxious, there may be an increased use of smoking, alcohol consumption, and illicit drug taking that may also pose risks for ocular health such as cataract, age-related macular degeneration, and vascular occlusions.

\section{Ethics}

No ethical permission was required for this review.

\section{Acknowledgments}

The authors thank Bill Duong, Sabrina Mourin, Aleyeh Rahimi, Bevan Thulkanam, and Mengqi Zhang for assisting with the literature search.

\section{Funding}

This review was not funded.

\section{Disclosure}

The authors declare no conflicts of interest.

\section{References}

1. Wu T, Jia X, Shi H, et al. Prevalence of mental health problems during the COVID-19 pandemic: a systematic review and meta-analysis. $J$ Affect Disord. 2021;281:91-98. doi:10.1016/j.jad.2020.11.117

2. Brooks SK, Webster RK, Smith LE, et al. The psychological impact of quarantine and how to reduce it: rapid review of the evidence. Lancet. 2020;395:912-920.

3. Malhi GS, Mann JJ. Depression. Lancet. 2018;392:2299-2312.

4. Richa S, Yazbek JC. Ocular adverse effects of common psychotropic agents: a review. CNS Drugs. 2010;24:501-526.

5. Brett J, Karanges EA, Daniels B, et al. Psychotropic medication use in Australia, 2007 to 2015: changes in annual incidence, prevalence and treatment exposure. Aust N Z J Psychiatry. 2017;51:990-999.

6. Keller MB. Long-term treatment strategies in affective disorders. Psychopharmacol Bull. 2002;36(Suppl 2):36-48.

7. van Dijk HG, Dapper EA, Vinkers CH. SSRIs and depressive symptoms in schizophrenia: a systematic review. Tijdschr Psychiatr. 2017;59:40-46.

8. Buoli M, Serati M, Cahn W. Alternative pharmacological strategies for adult ADHD treatment: a systematic review. Expert Rev Neurother. 2016;16:131-144. doi:10.1586/14737175.2016.1135735

9. Licht RW. Lithium: still a major option in the management of bipolar disorder. CNS Neurosci Ther. 2012;18:219-226. doi:10.1111/j.17555949.2011.00260.x

10. Park JSY, Sharma RA, Sharma V. Ophthalmic adverse effects of lithium. Int Clin Psychopharmacol. 2020;35:69-73. doi:10.1097/ YIC.0000000000000295

11. Sullivan PF, Neale MC, Kendler KS. Genetic epidemiology of major depression: review and meta-analysis. Am J Psychiatry. 2000;157:1552-1562.

12. Huider F, Milaneschi Y, van der Zee MD, et al. Major depressive disorder and lifestyle: correlated genetic effects in extended twin pedigrees. Genes. 2021;12:1509.

13. Park C, Rosenblat JD, Brietzke E, et al. Stress, epigenetics and depression: a systematic review. Neurosci Biobehav Rev. 2019;102:139-152.

14. Yang L, Zhao Y, Wang Y, et al. The effects of psychological stress on depression. Curr Neuropharmacol. 2015;13:494-504.

15. Rajkowska G, Miguel-Hidalgo JJ, Wei J, et al. Morphometric evidence for neuronal and glial prefrontal cell pathology in major depression. Biol Psychiatry. 1999;45:1085-1098.

16. Pitsillou E, Bresnehan SM, Kagarakis EA, et al. The cellular and molecular basis of major depressive disorder: towards a unified model for understanding clinical depression. Mol Biol Rep. 2020;47:753-770.

17. Mullins N, Lewis CM. Genetics of depression: progress at last. Curr Psychiatry Rep. 2017;19:43.

18. Mondal AC, Fatima M. Direct and indirect evidences of BDNF and NGF as key modulators in depression: role of antidepressants treatment. Int J Neurosci. 2019;129:283-296.

19. Zhang JC, Yao W, Hashimoto K. Brain-derived neurotrophic factor (BDNF)-TrkB signaling in inflammation-related depression and potential therapeutic targets. Curr Neuropharmacol. 2016;14:721-731.

20. Bahji A, Vazquez GH, Zarate CA Jr. Comparative efficacy of racemic ketamine and esketamine for depression: a systematic review and meta-analysis. J Affect Disord. 2021;278:542-555.

21. Ménard C, Hodes GE, Russo SJ. Pathogenesis of depression: insights from human and rodent studies. Neuroscience. 2016;321:138-162.

22. Caviedes A, Lafourcade C, Soto C, et al. BDNF/NF-kB signaling in the neurobiology of depression. Curr Pharm Des. 2017;23:3154-3163.

23. Lino de Oliveira C, Bolzan JA, Surget A, et al. Do antidepressants promote neurogenesis in adult hippocampus? A systematic review and meta-analysis on naive rodents. Pharmacol Ther. 2020;210:107515. 
24. Kohl C, Wang XD, Grosse J, et al. Hippocampal neuroligin-2 links early-life stress with impaired social recognition and increased aggression in adult mice. Psychoneuroendocrinology. 2015;55:128-143.

25. Feighner JP. Mechanism of action of antidepressant medications. J Clin Psychiatry. 1999;60(Suppl 4):4-13.

26. Lochmann D, Richardson T. Selective serotonin reuptake inhibitors. Handb Exp Pharmacol. 2019;250:135-144.

27. Jakubovski E, Johnson JA, Nasir M, et al. Systematic review and meta-analysis: dose-response curve of SSRIs and SNRIs in anxiety disorders. Depress Anxiety. 2019;36:198-212.

28. Locher C, Koechlin H, Zion SR, et al. Efficacy and safety of selective serotonin reuptake inhibitors, serotonin-norepinephrine reuptake inhibitors, and placebo for common psychiatric disorders among children and adolescents: a systematic review and meta-analysis. JAMA Psychiatry. 2017;74:1011-1020.

29. Sigel E, Ernst M. The benzodiazepine binding sites of GABA A receptors. Trends Pharmacol Sci. 2018;39:659-671.

30. American Psychiatric Associoation. Diagnostic and Statistical Manual of Mental Disorders: DSM-5 TM. 5th ed. Arlington, VA, US: American Psychiatric Publishing, Inc.; 2013.

31. Kessler RC, Chiu WT, Demler O, et al. Prevalence, severity, and comorbidity of 12-month DSM-IV disorders in the national comorbidity survey replication. Arch Gen Psychiatry. 2005;62:617-627.

32. Nowels MA, VanderWielen LM. Comorbidity indices: a call for the integration of physical and mental health. Prim Health Care Res Dev. 2018;19:96-98.

33. Giacobbe P, Flint A. Diagnosis and management of anxiety disorders. Continuum (Minneap, Minn). 2018;24:893-919.

34. Giotakos O. Neurobiology of emotional trauma. Psychiatriki. 2020;31:162-171.

35. Ehret M. Treatment of posttraumatic stress disorder: focus on pharmacotherapy. Ment Health Clin. 2019;9:373-382.

36. Miguel A, Henriques F, Azevedo LF, et al. Ophthalmic adverse drug reactions to systemic drugs: a systematic review. Pharmacoepidemiol Drug Saf. 2014;23:221-233.

37. Rief W, Nestoriuc Y, von Lilienfeld-Toal A, et al. Differences in adverse effect reporting in placebo groups in SSRI and tricyclic antidepressant trials: a systematic review and meta-analysis. Drug Saf. 2009;32:1041-1056.

38. Acan D, Kurtgoz P. Influence of selective serotonin reuptake inhibitors on ocular surface. Clin Exp Optom. 2017;100:83-86.

39. Işik-Ulusoy S, Ulusoy MO. Influence of different antidepressants on ocular surface in patients with major depressive disorder. $J$ Clin Psychopharmacol. 2021;41:49-52.

40. Koçer E, Koçer A, Özsütçü M, et al. Dry eye related to commonly used new antidepressants. J Clin Psychopharmacol. 2015;35:411-413.

41. van der Vaart R, Weaver MA, Lefebvre C, et al. The association between dry eye disease and depression and anxiety in a large population-based study. Am J Ophthalmol. 2015;159:470-474.

42. Galor A, Feuer W, Lee DJ, et al. Prevalence and risk factors of dry eye syndrome in a United States veterans affairs population. Am J Ophthalmol. 2011;152:377-384.e372.

43. Wen W, Wu Y, Chen Y, et al. Dry eye disease in patients with depressive and anxiety disorders in Shanghai. Cornea. 2012;31:686-692.

44. Zhang X, Yin Y, Yue L, et al. Selective serotonin reuptake inhibitors aggravate depression-associated dry eye via activating the NF- $\mathrm{BB}$ pathway. Invest Ophthalmol Vis Sci. 2019;60:407-419.

45. Wan KH, Chen LJ, Young AL. Depression and anxiety in dry eye disease: a systematic review and meta-analysis. Eye (Lond). 2016;30:1558-1567.

46. Becker C, Jick SS, Meier CR. Selective serotonin reuptake inhibitors and cataract risk: a case-control analysis. Ophthalmology. 2017;124:1635-1639.

47. Chou PH, Chu CS, Chen YH, et al. Antidepressants and risk of cataract development: a population-based, nested case-control study. $J$ Affect Disord. 2017;215:237-244.

48. Erie JC, Brue SM, Chamberlain AM, et al. Selective serotonin reuptake inhibitor use and increased risk of cataract surgery: a population-based, case-control study. Am J Ophthalmol. 2014;158:192-197.e191.

49. Etminan M, Mikelberg FS, Brophy JM. Selective serotonin reuptake inhibitors and the risk of cataracts: a nested case-control study. Ophthalmology. 2010;117:1251-1255.

50. Klein BEK, Klein R, Lee KE, et al. Drug use and five-year incidence of age-related cataracts: the Beaver Dam Eye Study. Ophthalmology. 2001;108:1670-1674.

51. Zanon-Moreno V, Melo P, Mendes-Pinto MM, et al. Serotonin levels in aqueous humor of patients with primary open-angle glaucoma. Mol Vis. 2008;14:2143-2147.

52. Kisilevsky E, Margolin EA. Case of rapid bilateral cataract development in teenager using selective serotonin reuptake inhibitors. Can J Ophthalmol. 2014;49:e114-115.

53. Kirkham J, Seitz D. Evidence of ocular side effects of SSRIs and new warnings. Evid Based Ment Health. 2017;20:27.

54. Symes RJ, Etminan M, Mikelberg FS. Risk of angle-closure glaucoma with bupropion and topiramate. JAMA Ophthalmol. 2015;133:1187-1189.

55. Chen HY, Lin CL, Lai SW, et al. Association of selective serotonin reuptake inhibitor use and acute angle-closure glaucoma. J Clin Psychiatry. 2016;77:e692-696.

56. Zheng W, Dryja TP, Wei Z, et al. Systemic medication associations with presumed advanced or uncontrolled primary open-angle glaucoma. Ophthalmology. 2018;125:984-993.

57. Wu A, Khawaja AP, Pasquale LR, et al. A review of systemic medications that may modulate the risk of glaucoma. Eye (Lond). 2020;34:12-28.

58. Stein JD, Talwar N, Kang JH, et al. Bupropion use and risk of open-angle glaucoma among enrollees in a large U.S. managed care network. PLoS One. 2015;10:e123682.

59. Masís M, Kakigi C, Singh K, et al. Association between self-reported bupropion use and glaucoma: a population-based study. Br J Ophthalmol. 2017;101:525-529.

60. Barow E, Schneider SA, Bhatia KP, et al. Oculogyric crises: etiology, pathophysiology and therapeutic approaches. Parkinsonism Relat Disord. 2017;36:3-9.

61. Solberg M, Koht J. Oculogyric crises. Tremor Other Hyperkinet Mov (NY). 2017;7:491.

62. Kahraman N, Durmaz O, Durna MM. Mirtazapine-induced acute angle closure. Indian J Ophthalmol. 2015;63:539-540. 
63. Dorell K, Cohen MA, Huprikar SS, et al. Citalopram-induced diplopia. Psychosomatics. 2005;46:91-93.

64. Alao A, Lewkowicz C. Seeing double: sertraline and diplopia: a case report. Int J Psychiatry Med. 2015;49:107-110.

65. Bicer T, Kosker M, Celikay O, et al. A case of retrobulbar optic neuritis caused by duloxetine. Cutan Ocul Toxicol. 2016;35:251-253.

66. Shifera AS, Leoncavallo A, Sherwood M. Probable association of an attack of bilateral acute angle-closure glaucoma with duloxetine. Ann Pharmacother. 2014;48:936-939.

67. Botha VE, Bhikoo R, Merriman M. Venlafaxine-induced intraocular pressure rise in a patient with open angle glaucoma. Clin Exp Ophthalmol. 2016;44:734-735.

68. Varatharaj A, Moran J. Pendular nystagmus associated with venlafaxine overdose: a forme fruste of the serotonin syndrome? BMJ Case Rep. 2014;2014:bcr2013202106.

69. Garakani A, Murrough JW, Freire RC, et al. Pharmacotherapy of anxiety disorders: current and emerging treatment options. Front Psychiatry. 2020;11:595584.

70. Szabadi E, Gaszner P, Bradshaw CM. Interaction of desipramine and amitriptyline with adrenergic mechanisms in the human iris in vivo. Eur J Clin Pharmacol. 1981;19:403-408.

71. Ciobanu AM, Dionisie V, Neagu C, et al. Psychopharmacological treatment, intraocular pressure and the risk of glaucoma: a review of literature. J Clin Med. 2021;10:2947.

72. Lucca JM, Ramesh M, Parthasarathi G, et al. Lorazepam-induced diplopia. Indian J Pharmacol. 2014;46:228-229.

73. Hassan Basri M, Khoo CS, Che Hamzah J. Dilated pupils in an anxious patient. Acta Neurol Belg. 2021;121:573-574.

74. Attaway A, Sroujieh L, Mersfelder TL, et al. "Ping-pong gaze" secondary to monoamine oxidase inhibitor overdose. $J$ Pharmacol Pharmacother. 2016;7:34-37.

75. Kawalec P, Cierniak A, Pilc A, et al. Pregabalin for the treatment of social anxiety disorder. Expert Opin Investig Drugs. 2015;24:585-594.

76. Generoso MB, Trevizol AP, Kasper S, et al. Pregabalin for generalized anxiety disorder: an updated systematic review and meta-analysis. Int Clin Psychopharmacol. 2017;32:49-55.

77. Zaccara G, Gangemi P, Perucca P, et al. The adverse event profile of pregabalin: a systematic review and meta-analysis of randomized controlled trials. Epilepsia. 2011;52:826-836.

78. Tanyıldız B, Kandemir B, Mangan MS, et al. Bilateral serous macular detachment after attempted suicide with pregabalin. Turk J Ophthalmol. 2018;48:254-257.

79. Mousailidis G, Papanna B, Salmon A, et al. Pregabalin induced visual hallucinations - a rare adverse reaction. BMC Pharmacol Toxicol. 2020;21:16.

80. Browne MJ, Zakrzewski H, Carleton B, et al. Association of gabapentin or pregabalin use and incidence of acute angle-closure glaucoma. J Glaucoma. 2019;28:777-779. doi:10.1097/IJG.0000000000001330

81. Van Rheenen TE, Meyer D, Neill E, et al. Mental health status of individuals with a mood-disorder during the COVID-19 pandemic in Australia: initial results from the COLLATE project. $J$ Affect Disord. 2020;275:69-77. doi:10.1016/j.jad.2020.06.037

82. Baxter AJ, Scott KM, Ferrari AJ, et al. Challenging the myth of an "epidemic" of common mental disorders: trends in the global prevalence of anxiety and depression between 1990 and 2010. Depress Anxiety. 2014;31:506-516. doi:10.1002/da.22230

83. Kimko HC, Cross JT, Abernethy DR. Pharmacokinetics and clinical effectiveness of methylphenidate. Clin Pharmacokinet. 1999;37:457-470. doi:10.2165/00003088-199937060-00002

84. Barkley RA, McMurray MB, Edelbrock CS, et al. Side effects of methylphenidate in children with attention deficit hyperactivity disorder: a systemic, placebo-controlled evaluation. Pediatrics. 1990;86:184-192. doi:10.1542/peds.86.2.184

85. Stępnicki P, Kondej M, Kaczor AA. Current concepts and treatments of schizophrenia. Molecules. 2018;23(8):2087. doi:10.3390/ molecules 23082087

86. Leucht S, Corves C, Arbter D, et al. Second-generation versus first-generation antipsychotic drugs for schizophrenia: a meta-analysis. Lancet. 2009;373:31-41. doi:10.1016/S0140-6736(08)61764-X

87. Milaneschi Y, Simmons WK, van Rossum EFC, et al. Depression and obesity: evidence of shared biological mechanisms. Mol Psychiatry. 2019;24:18-33.

88. Fluharty M, Taylor AE, Grabski M, et al. The association of cigarette smoking with depression and anxiety: a systematic review. Nicotine Tob Res. 2017;19:3-13. doi:10.1093/ntr/ntw140

89. Piper ME, Kenford S, Fiore MC, et al. Smoking cessation and quality of life: changes in life satisfaction over 3 years following a quit attempt. Ann Behav Med. 2012;43:262-270. doi:10.1007/s12160-011-9329-2

90. Karimi S, Arabi A, Shahraki T. Alcohol and the Eye. J Ophthalmic Vis Res. 2021;16:260-270. doi:10.18502/jovr.v16i2.9089

91. Davis L, Uezato A, Newell JM, et al. Major depression and comorbid substance use disorders. Curr Opin Psychiatry. 2008;21:14-18. doi:10.1097/YCO.0b013e3282f32408

92. Dhingra D, Kaur S, Ram J. Illicit drugs: effects on eye. Indian J Med Res. 2019;150:228-238. doi:10.4103/ijmr.IJMR_1210_17

93. Sarris J. Herbal medicines in the treatment of psychiatric disorders: 10-year updated review. Phytother Res. 2018;32:1147-1162. doi:10.1002/ptr.6055

94. Yeung KS, Hernandez M, Mao JJ, et al. Herbal medicine for depression and anxiety: a systematic review with assessment of potential psycho-oncologic relevance. Phytother Res. 2018;32:865-891. doi:10.1002/ptr.6033

95. Stahl SM, Grady MM. Differences in mechanism of action between current and future antidepressants. J Clin Psychiatry. 2003;64(Suppl 13):13-17.

96. Gerhard DM, Wohleb ES, Duman RS. Emerging treatment mechanisms for depression: focus on glutamate and synaptic plasticity. Drug Discov Today. 2016;21:454-464. doi:10.1016/j.drudis.2016.01.016

97. Zheng W, Cai DB, Xiang YQ, et al. Adjunctive intranasal esketamine for major depressive disorder: a systematic review of randomized double-blind controlled-placebo studies. J Affect Disord. 2020;265:63-70. doi:10.1016/j.jad.2020.01.002

98. García-Gutiérrez MS, Navarrete F, Gasparyan A, et al. Cannabidiol: a potential new alternative for the treatment of anxiety, depression, and psychotic disorders. Biomolecules. 2020;10(11):1575. doi:10.3390/biom10111575

99. Yokoi Y, Narita Z, Sumiyoshi T. Transcranial direct current stimulation in depression and psychosis: a systematic review. Clin EEG Neurosci. 2018;49(2):93-102. doi:10.1177/1550059417732247

100. Salehpour F, Mahmoudi J, Kamari F, et al. Brain photobiomodulation therapy: a narrative review. Mol Neurobiol. 2018;55:6601-6636. 


\section{Publish your work in this journal}

Clinical Optometry is an international, peer-reviewed, open access journal publishing original research, basic science, clinical and epidemiological studies, reviews and evaluations on clinical optometry. All aspects of patient care are addressed within the journal as well as the practice of optometry including economic and business analyses. Basic and clinical research papers are published that cover all aspects of optics, refraction and its application to the theory and practice of optometry. The manuscript management system is completely online and includes a very quick and fair peer-review system, which is all easy to use. Visit http://www.dovepress.com/testimonials.php to read real quotes from published authors.

Submit your manuscript here: https://www.dovepress.com/clinical-optometry-journal 